\title{
The California Critical Thinking Skills Test And Business School Performance
}

\author{
Peter Bycio, Xavier University, USA
}

Joyce S. Allen, Xavier University, USA

\begin{abstract}
An intent of many business programs is to enhance the critical thinking capabilities of their students. Since AACSB accreditation requires evidence that business schools fulfill their goals, our students were required to take the California Critical Thinking Skills Test (CCTST). As expected, the CCTST was significantly related to SAT performance and to Business Core GPA. Nonetheless, the especially strong relationships with components thought to emphasize critical thinking, such as performance in the business capstone course, were not observed. SAT scores alone predicted $56 \%$ of the variance in CCTST. None of our other predictors added significantly to this total.
\end{abstract}

Keywords: critical thinking, outcomes assessment, AACSB.

\section{INTRODUCTION}

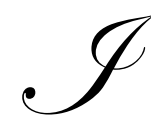

ncreasingly, the agencies responsible for accrediting programs in higher education have been requiring direct evidence that universities are fulfilling their stated missions. This is true both for the groups that oversee general education, for example, the North Central Association $(1991,2003)$ and those who accredit specific programs such as the AACSB International--The Association to Advance Collegiate Schools of Business, (2006).

As the body that deals exclusively with the accreditation of business programs per se, AACSB publishes 80 pages of standards (AACSB-International, 2006) to provide schools with detailed guidelines concerning the criteria the review team will use in its evaluation. Among other things, certain content areas are expected to be covered in both undergraduate and MBA programs. These include ethical and legal responsibilities, financial theories, domestic and global economic environments, as well as group and individual organizational dynamics (AACSBInternational, 2006, p. 71).

Besides specifying areas of content coverage, AACSB-International (2006) expects schools to provide evidence that "learning occurs for each of the learning goals" (AACSB-International, 2006, p. 62). A variety of methods are delineated for providing evidence of learning achievement and examples of how these approaches might be used (cf., AACSB-International, 2006, pgs 62-68).

One of the reasons that AACSB-International (2006) is open to the use of a variety of methods in relation to assurance of learning is that no single "correct" approach exists. For example, a variety of course embedded measurement approaches are endorsed (e.g., papers and applied projects required to successfully compete a course) as are standardized achievement tests. The field of study concerned with examining and documenting the advantages and disadvantages associated with various assessment approaches is generically referred to as educational outcomes assessment (DeMong, Lindgren, \& Perry, 1994; Palomba \& Banta, 1999). In line with the recommendations of AACSB-International (2006), a wide range of methods have been proposed and used by universities to provide evidence of learning achievement (DeMong et al., 1994; Herring \& Izard, 1992; Herring, Scheiner, \& Williams, 1989; Palomba \& Banta, 1999; Paskow \& Francis, 1990). 
One of the standardized approaches to assessing learning achievement that has been successfully used is the Educational Testing Service (ETS) Major Field Achievement Test in Business (MFAT-B). This 120 item multiple choice assessment has been shown to correlate strongly with undergraduate student grade point average (GPA) in business core (GPA-BUS) classes (Allen \& Bycio, 1997; Bycio \& Allen, 2007). As such, performance on the MFAT-B provides a basis for comparing student achievement across business schools.

Many, if not all business programs, have academic goals that go beyond providing business knowledge per se. For example, most academic programs aim to foster critical thinking. While many perspectives on the meaning of critical thinking exist, an international multidisciplinary panel characterized it as "the process of purposeful, self regulatory judgment. This process gives reasoned consideration to evidence, content, conceptualizations, methods, and criteria" (The APA Delphi Report, 1990). As the definition implies, critical thinking goes beyond the acquisition of knowledge and it is seen as a capability that has the potential to make an on-going contribution to quality of life in general (Facione, 2007). The California Critical Thinking Skills Test (CCTST; Facione, 2000), a 34-item standardized exam was developed to assess critical thinking in line with the conceptualization forwarded by the APA Delphi Report (1990). Analysis, interpretation, and evaluation are among the attributes of interest identified by the Delphi group.

\section{THE CURRENT INVESTIGATION}

As part of an AACSB reaffirmation effort, the CCTST was administered at the authors' business school. The test was used because critical thinking per se was one of six competencies that our faculty intended to develop in our undergraduate population. While the performance of the students was obviously of interest, there was a need to further examine the validity of the CCTST from an outcomes assessment perspective. In particular, those responsible for designing and implementing accreditation efforts need to examine the degree to which the CCTST provides useful assessment information beyond that provided by indices of academic aptitude such as the Scholastic Aptitude Test (SAT), or by business specific tests such as the MFAT-B. There are both theoretical and practical considerations involved. For example, the CCTST test requires 45 minutes of administration time and costs of approximately five dollars per examinee. These could be viewed as substantial depending upon the scope of the accreditation effort and the financial resources of a given school. As such, we examined the degree to which the most recent version of the CCTST (Form 2000) provided useful student outcomes information in the context of a broader AACSB reaffirmation effort.

Very little published research pertaining to the CCTST exists beyond that provided in the 2002 CCTST test manual (Facione, Facione, Blohm, \& Giancario, 2002). For example, we are unaware of any study that examines the test as part of a business school outcomes program. As such, this study is exploratory in nature. Below, we raise a series of questions involving (for example) the relationship of the CCTST to the SAT, student GPAs, and the MFAT-B. Data pertaining to these issues will be of interest to those designing AACSB outcomes efforts and to those looking to use the CCTST as a reflection of critical thinking per se.

1. Not surprisingly, earlier forms of the CCTST (Forms A and B) were significantly related to academic aptitude as reflected by performance on SAT Verbal (SAT-V) and Math (SAT-M) exams. Since Form 2000 retains 22 of the 36 items from the earlier versions, we expected similarly moderate associations between the SAT and the CCTST 2000. Nonetheless, if the associations are too strong, the CCTST might simply reflect a general capability to deal with standardized multiple choice academic questions (test taking ability, cf. DeMong et al., 1994) as opposed to the intended broad cross-situational attribute described in the APA Delphi Report (1990).

2. Moderate associations are expected between the CCTST and the MFAT-B because both are standardized multiple choice tests and because some of the MFAT-B items involve more than mere knowledge of business concepts given that application and interpretation are required as well. Nonetheless, as with the SAT, if the associations are especially strong, the incremental value of administering the CCTST as part of an AACSB accreditation effort would be called into question. 
3. To the extent that CCTST performance reflects something more than test taking ability, we would expect it to relate to certain expects of a curriculum more strongly than others. For example, our undergraduate business curriculum ends with a capstone course that is intended (among other things) to assess student capabilities to analyze and respond to multifaceted business cases. Stated differently, the capstone course associated with each of our business majors is intended to place demands on students that better reflect the specific attributes that the CCTST is intended to measure (e.g., analysis, interpretation and evaluation). As such, we expect the CCTST and business capstone grade (CAPSTONE) relationship to be among the strongest observed in the study.

4. Our business curriculum is nested within a substantial liberal arts program. Only half of the credits required for our undergraduate business degree are from the business college. Although some believe this has put our business school at a competitive disadvantage, the relative emphasis on liberal arts has not changed because of a belief that much of our non-business curriculum more directly fosters the development of many of the attributes targeted by the CCTST. Given the nature of this liberal arts and business mix, critical thinking as conceptualized on the CCTST would be expected to relate more strongly to performance in broad curriculum (cf., Facione, 2007) than to the business content only. As such, we expected the correlation between the CCTST and overall university GPA (GPA-U) to be significantly larger than the CCTST- GPA-BUS relationship.

5. The CCTST 2000 manual (Facione et al., 2002) states that there is no reason to believe that the test unfairly discriminates among students based on their major. Nonetheless, some differences among business majors have been observed on other standardized tests. For example, with regard to the MFAT-B, Allen and Bycio (1997) reported that those in Accounting and Finance performed significantly better than students in other business majors. Importantly, these differences were mirrored by similar variations in SAT profiles across majors. Thus, it was unclear whether the differences by business major reflected test content biases or test taking ability. In any case, the Allen and Bycio (1997) finding leaves open the possibility of CCTST differences, especially if there are SAT variations across majors.

6. Gender-based differences were not expected on the CCTST 2000 given that these were not an issue with the earlier Forms A and B (cf. Facione et al., 2002). Nonetheless, further investigation would be called for (e.g., Buckless, Lipe, \& Ravenscroft, 1991) if gender variations were observed.

7. Student motivation has been found to predict performance on standardized tests in AACBC accreditation contexts. For example, Bycio and Allen (2007) asked students about the degree to which they were motivated to take the MFAT-B and the extent to which the maintenance of AACSB accreditation was important to them. They found that student motivation was associated with MFAT-B performance even after SAT and GPA variables were controlled for. Since the CCTST was part of the accreditation effort, we expected that the level of importance students ascribed to reaffirmation would be predictive in this context as well.

\section{METHOD}

\section{Sample and Procedure}

All graduating business majors were required to complete a series of assessments as part of a AACSB reaffirmation effort. The first of these was the MFAT-B which was administered to the students in one large group (cf. Bycio and Allen, 2007). Prior to MFAT-B administration, the senior author delivered a 10 minute presentation to students concerning the importance of AACSB reaffirmation. Among other things, the long-term multifaceted nature of the accreditation process was explained and the AACSB website with the school accreditation status was displayed. The role that AACSB plays in U.S. News and World Report rankings of business programs was addressed as well. After the presentation, students were asked to rate the degree to which AACSB reaffirmation was important to them (see AACSB Importance below). 
In subsequent weeks, the students were also required to complete the CCTST 2000. However, unlike the MFAT-B, the CCTST was administered to students in their respective capstone classes. To promote standard test conditions the senior author (a department chair at the time) visited each capstone class to oversee the process.

Of the 185 graduating business majors, $162(88 \%)$ were in attendance to take the CCTST. Consistent with university guidelines, students had the option to have their data excluded from this study. Thirty-one students (19\%) indicated they did not want to be included. The resulting sample size was 131 . Fifty-four percent were male and forty-six percent were female.

\section{Data Collection of Standardized Indices}

SAT scores and all GPAs were obtained directly from student records. The MFAT-B and CCSTS 2000 results were collected as part of the AACSB reaffirmation effort.

\section{AACSB Importance}

Following a presentation concerning the role that AACSB plays in accrediting business schools, students were asked "As a graduating student, how important is it to you that the college of business continues to be accredited by the AACSB?" A four-point response scale was used ( $1=$ "no importance" - $4=$ "all important").

\section{Analysis}

Testing five of the seven research questions required computing correlations and/or comparing the size of the correlations involving the CCTST and the various predictors. When the size of correlations were compared, the t-test formula for dependent correlations given by Cohen and Cohen (1983, pgs. 56-57) was used, for example, to determine if the CAPSTONE had, relatively speaking, a significantly stronger association with CCTST scores. Analysis of variance (cf. Winer, 1971) was used to test the two remaining questions. In particular, F-tests were used to evaluate the possibility of significant differences in CCTST by business major and gender.

Also, multiple regression analysis (cf. Cohen \& Cohen, 1983) was used to explore the degree to which the combining different types of variables (e.g., SAT, MFAT-B, GPAs, and AACSB-Importance) could account for CCTST performance. As a follow up, stepwise regression was employed to identify the smallest set of variables that could be used to optimally predict the CCTST. As such, it provides information concerning the degree to which each variable had a significant, unique association with CCTST scores (cf. Cohen \& Cohen, 1983, pgs. 123-125).

\section{RESULTS}

\section{Descriptive Statistics}

Table 1 shows the means, standard deviations and correlations among all the variables. The sample sizes vary due to missing data. This is especially relevant to findings involving the SAT, where $\underline{\mathrm{n}}=76$. This difference relative to the GPA-based findings (where $\underline{N}=131$ ) reflects the fact that the SAT was not necessarily required to gain admission to the university. For clarity, in reporting the results below, the sample size associated with each individual finding is noted.

\section{Overall CCTST Performance}

The mean CCTST score in our sample was $\underline{\mathrm{M}}=20.33(\underline{\mathrm{N}}=112)$. This score was virtually identical to the mean of 20 reported by the testing company, which includes students who did not want their data used in this study. 
Table 1: Descriptive Statistics and Correlations Among All Study Variables

\begin{tabular}{|c|c|c|c|c|c|c|c|c|c|c|}
\hline & $N$ & $M$ & $S D$ & 1 & 2 & 3 & 4 & 5 & 6 & 7 \\
\hline 1. CCTST & 112 & 20.33 & 4.75 & & & & & & & \\
\hline 2. MFAT-B & 131 & 161.78 & 13.21 & $\begin{array}{c}.63 \\
(112)\end{array}$ & & & & & & \\
\hline 3. SAT-V & 76 & 562.24 & 79.78 & $\begin{array}{c}.66 \\
(68) \\
\end{array}$ & $\begin{array}{c}.66 \\
(76) \\
\end{array}$ & & & & & \\
\hline 4. SAT-M & 76 & 572.24 & 76.41 & $\begin{array}{c}.69 \\
(68)\end{array}$ & $\begin{array}{c}.64 \\
(76)\end{array}$ & $\begin{array}{c}.62 \\
(76)\end{array}$ & & & & \\
\hline 5. GPA-BUS & 131 & 3.21 & .56 & $\begin{array}{c}.47 \\
(112)\end{array}$ & $\begin{array}{c}.62 \\
(131)\end{array}$ & $\begin{array}{c}.52 \\
(76)\end{array}$ & $\begin{array}{c}.59 \\
(76)\end{array}$ & & & \\
\hline 6. GPA-U & 131 & 3.21 & .49 & $\begin{array}{c}.46 \\
(112)\end{array}$ & $\begin{array}{c}.59 \\
(131)\end{array}$ & $\begin{array}{c}.50 \\
(76) \\
\end{array}$ & $\begin{array}{c}.59 \\
(76) \\
\end{array}$ & $\begin{array}{c}.92 \\
(131)\end{array}$ & & \\
\hline 7. CAPSTONE & 115 & 3.24 & .68 & $\begin{array}{c}.21 \\
(97)\end{array}$ & $\begin{array}{c}.30 \\
(115)\end{array}$ & $\begin{array}{c}.36 \\
(64)\end{array}$ & $\begin{array}{l}.32 \\
(64)\end{array}$ & $\begin{array}{c}.43 \\
(115)\end{array}$ & $\begin{array}{c}.48 \\
(115)\end{array}$ & \\
\hline 8. AACSB-IMP & 131 & 3.01 & .89 & $\begin{array}{c}.25 \\
(112)\end{array}$ & $\begin{array}{c}.25 \\
(131)\end{array}$ & $\begin{array}{c}.10 \\
(76)\end{array}$ & $\begin{array}{c}.21 \\
(76)\end{array}$ & $\begin{array}{c}.20 \\
(131)\end{array}$ & $\begin{array}{c}.15 \\
(131)\end{array}$ & $\begin{array}{c}.07 \\
(131)\end{array}$ \\
\hline
\end{tabular}

Note. The sample size associated with each correlation is presented in parentheses. When $n=76$, correlations of .27 are significant at the $p<.01$ level. When $N=131$, correlations of .23 are significant at the $p<.01$ level.

\section{SAT, MFAT-B, GPA, and CCTST Performance}

As Table 1 shows, both SAT-V $(\underline{\mathrm{r}}=.66, \underline{\mathrm{p}}<.01, \underline{\mathrm{n}}=68)$ and SAT-M $(\underline{\mathrm{r}}=.69, \underline{\mathrm{p}}<.01, \underline{\mathrm{n}}=68)$ are significant and moderately large predictors of CCTST performance. Moreover, CCTST was also strongly related to the MFAT-B $(\underline{\mathrm{r}}=.63, \underline{\mathrm{p}}<.01, \underline{\mathrm{n}}=112)$. However, contrary to expectations, the CCTST was not an especially strong predictor of performance in the business capstone course $(\underline{\mathrm{r}}=.21, \underline{\mathrm{p}}<.05, \underline{\mathrm{n}}=97)$. In fact, tests comparing dependent correlations revealed that both SAT-V $(\mathrm{T}(53)=-3.13, \mathrm{p}<.05)$ and SAT-M $(\mathrm{T}(53)=-3.40, \mathrm{p}<.05)$ were significantly better predictors of the CCTST than was the CAPSTONE.

Finally, the CCTST scores predicted overall GPA-U $(\underline{r}=.41, \underline{p}<.01, \underline{n}=97)$, but the strength of the relationship was not significantly better than that for GPA-BUS $(\underline{r}=.42, \underline{p}<.01, \underline{n}=97)$.

\section{CCTST Performance by Major and Gender}

Regarding the possibility of differences in CCTST performance across business majors, the authors confined their analysis to those specialties with at least 20 students (i.e., Finance $\underline{n}=27$, ManagementEntrepreneurship-Human Resources $\underline{\mathrm{n}}=23$, and Marketing $\underline{\mathrm{n}}=34)$. There were no significant differences $(\underline{\mathrm{F}}(2,81)$ $=2.18$, n.s.). Finally, analysis of variance pertaining to gender and the CCTST revealed no significant differences $(\underline{\mathrm{F}}(1,110)=.25$, n.s. $)$.

\section{Accreditation Importance and CCTST Performance}

As shown in Table 1, the mean student response regarding the importance of AACSB reaffirmation was 3.01 out of 4. This is not especially high given the efforts of the senior author to explain the value of AACSB reaffirmation to the students. Nonetheless, the importance of accreditation was a significant predictor of CCTST performance $(\underline{\mathrm{r}}=.25, \underline{\mathrm{p}}<.01, \underline{\mathrm{n}}=112)$, although the size of the correlation was significantly smaller than most of the other predictors (see Table 1).

\section{SAT, MFAT-B, GPA, and Accreditation Importance as a Predictor Set}

As presented in Table 2, multiple regression was used to examine the degree to which our variable set made significant contributions to the prediction of CCTST performance. As a group, the predictors accounted for $60 \%$ of 
the variance in CCTST scores.

Table 3 shows the stepwise regression findings. Only the two SAT-based predictors (SAT-M and SAT-V) were required to account for $56 \%$ of the CCTST variance. None of the GPAs, MFAT-B performance, or accreditation importance added significantly to the prediction.

Table 2: SAT, GPA, and Motivation Variables As Predictors of CCTST Performance

\begin{tabular}{lcl}
\hline & $F$ & $p$ \\
\hline 1. SAT-V & 65.60 & .01 \\
\hline 2. SAT-M & 19.32 & .01 \\
\hline 3. GPA-BUS & .18 & n.s. \\
4. GPA-U & .03 & n.s. \\
5. MFAT-B & 3.45 & n.s. \\
6. AACSB-IMPT. & 1.35 & n.s. \\
Total Model ${ }^{2}=$ & .60 & \\
\hline Note. These results pertain to the sample with missing cases deleted $n=68$.
\end{tabular}

Table 3: Stepwise Multiple Regression Predicting CCTST Performance

\begin{tabular}{|c|c|c|c|c|}
\hline & 2 & 2 & & \\
\hline & Partial $\mathrm{r}$ & Model $\mathrm{r}$ & $F$ & $p$ \\
\hline 1. SAT-M & .48 & .48 & 61.63 & .00 \\
\hline 2. SAT-V & .08 & .56 & 11.86 & .00 \\
\hline
\end{tabular}

Note. These results pertain to the sample with missing cases deleted. $n=68$

\section{DISCUSSION}

\section{CCTST Performance and General Intellectual Ability}

As expected, significant associations were observed between CCTST 2000 scores and both the SAT-V and SAT-M. Our correlations (.66 and .68, respectively) were slightly higher than those reported for nursing students (.55 and .44 respectively) using an earlier form of the test (CCTST 2002 Manual; Facione et al., 2002 p. 20). Also as expected, the CCTST 2000 was significantly related to MFAT-B performance and to various GPAs (GPA-BUS and GPA-U). On the face of it, all of these findings are supportive for a test intended to assess critical thinking, as are the lack of major or gender differences in the scores.

Notwithstanding the above positives, some important expectations were not supported. For example, the magnitude of the CCTST-CAPSTONE relationship was not significantly larger than the relationships involving overall GPAs. In fact, the SAT-CCTST associations noted earlier were significantly stronger than the CCTSTCAPSTONE $(r=.21)$. Further, the CCTST had relationships that were equal in magnitude with GPA-U and GPABUS, even though approximately one half the former consisted of liberal arts courses. These findings are less positive for the CCTST because one would want a measure of critical thinking to have its strongest relationships with courses and curriculum intended to especially challenge students to move beyond "just the facts". Instead, the equally strong relationships involving the SAT, the GPAs and the MFAT-B suggest that the CCTST is potentially strongly influenced by general test taking ability. This possibility was reinforced by the stepwise regression analysis where the SAT scores were the only predictors retained and they accounted for almost as much variance in the CCTST (56\%) as the entire predictor set (60\%). By comparison, Bycio and Allen (2007) found that SAT, GPA, and Student Motivation components each contributed significant unique variance to the prediction of the MFAT-B. 


\section{Limitations and Future Research}

A limitation of this investigation is that the findings pertain only to one group of graduates at a single university. As far as we know, this is the only examination of the CCTST involving business students.

Beyond generalizability issues per se, the design of our study was purely correlational which lacks the advantages associated with controlled experiments (cf. Cook \& Campbell, 1979). As such, for example, some of our expectations may have not received support because the business capstone and liberal arts curricula did not place especially strong demands on critical thinking as assessed by the CCTST. Consistent with this possibility, in an experiment cited in the CCTST 2002 Test Manual (Facione et al. 2002; p. 19), undergraduates who took a semesterlong course in critical thinking per se, performed significantly better on an earlier form of the CCTST than those who did not. Perhaps if our business faculty had been asked specifically to design content around the dimensions of critical thinking that underlie the CCTST, a stronger association to the capstone grades would have been observed. Future research concerning the CCTST should involve building faculty awareness and consensus around the conceptualization of critical thinking as put forward in the APA Delphi Report (1990). Finally, should greater confidence be established in the CCTST as a measure of critical thinking per se, it would be of obvious interest to employ a pre-post test experimental design (cf. Cook \& Campbell, 1979) to evaluate the degree of change associated with the completion of a business degree.

\section{CONCLUSION}

Confirmation of moderately strong relationships between general intellect and CCTST performance is important because it implies that schools with strong SAT profiles will likely have a performance edge relative to those with less stringent admission requirements. As such, from a macro perspective, CCTST scores cannot be meaningfully compared across institutions without also accounting for possible differences in SAT indices. Similarly, since AACSB accreditation importance was significantly related to CCTST performance, differences in student motivation must also be accounted for when making comparisons across business schools. Importantly, these cautions are not unique to the CCTST. Similar issues are associated with the interpretation of the MFAT-B as well (cf., Bycio \& Allen (2007).

\section{AUTHOR INFORMATION}

Peter Bycio is an independent consultant based in Cincinnati Ohio, USA. As a former professor and department chair in the Williams College of Business at Xavier University, Dr. Bycio has been a teacher, scholar and consultant in the areas of managerial behavior and human resource management. He has published research concerning managerial selection, performance management, leadership, organizational commitment, employee absenteeism and turnover, as well as outcomes assessment.

Joyce S. Allen is an Associate Professor of Accountancy at Xavier University in Cincinnati, Ohio. Professor Allen has published research concerning financial accounting and reporting, accounting education, leadership, and outcomes assessment. She teaches financial accounting and reporting in the undergraduate, MBA and Executive MBA programs.

\section{REFERENCES}

1. AACSB-International (2006). Standards for business accreditation, St. Louis, MO. AASCB.

2. Allen, J.S., \& Bycio, P. (1997). An evaluation of the educational testing service major field achievement test in business. Journal of Accounting Education, 15, 503-514.

3. APA Delphi Report (1990). Critical thinking: A statement of expert consensus for purposes of educational assessment and instruction. The California Academic Press. Millbrae, CA. ERIC doc. NO: ED 315423. 
4. Buckless, F.A., Lipe, M.G., \& Ravenscroft, S.P. (1991). Do gender effects on accounting course performance persist after controlling for gender academic aptitude?. Issues in Accounting Education, 6, 248-261.

5. Bycio, P., \& Allen, J.S. (2007). Factors related to performance on the ETS major field achievement test in business. Journal of Education for Business, 82, 196-201.

6. California Critical Thinking Skills Test CCTST-2000 (2000). California Academic Press. Santa Clara.

7. Cook, T.D., \& Campbell, D.T. (1979). Quasi-experimentation, design \& analysis issues for field settings. Chicago, IL: Rand McNally.

8. Cohen, J., \& Cohen, P. (1983). Applied multiple regression/correlation analysis for the behavioral sciences. 2nd ed. Hillsdale, NJ: Lawrence Erlbaum.

9. DeMong, R.F., Lindgren, J.H., \& Perry, S.E. (1994). Designing an assessment program in accounting. Issues In Accounting Education, 9, 11-27.

10. Educational Testing Service. (1993). Major field tests comparative data guide. Princeton, NJ.

11. Facione, P.A. (2000). The california critical thinking skills test: cctst - 2000. California Academic Press.

12. Facione, P.A., Facione, N.C., Blohm, S.W. \& Giancario, C.F. (2002). The california critical thinking skills test manual. California Academic Press.

13. Facione, P.A. (2007). Critical thinking: what it is and why it counts: 2007 update. Insight Assessment/California Academic Press.

14. Herring, H.C., \& Izard, C.D. (1992). Outcome assessment of accounting majors. Issues in Accounting Education, 7, 1-17.

15. Herring, H.C., Scheiner, J.H., \& Williams, J.R. (1989). The development of education research in accounting. Issues in Accounting Education, 4, 48-57.

16. NCA Quarterly. (1991). Assessing student academic achievement. Tempe, AZ: North Central Association of Colleges and Schools.

17. North Central Association (2003). Accreditation of higher education institutions: An overview. Chicago, IL: The Higher Learning Commission, NCA

18. Paskow, J., \& Francis, E.A. (1990). Assessment programs and projects: A directory. Washington, DC: American Association for Higher Education.

19. Palomba, C. A., \& Banta, T.W. (1999). Assessment essentials, planning, implementing, and improving assessment in higher education. San Francisco: Josey-Bass.

20. Scholastic Aptitude Test (2007). www.collegeboard.com.

21. Winer, B.J. (1971). Statistical principles in experimental design. 2nd ed. New York: McGraw-Hill. 